\title{
REVIEW
}

\section{Microbial functional genes associated with coral health and disease}

\author{
Zoe A. Pratte* \\ Florida International University, Department of Biological Sciences, 11200 SW 8th Street, Miami, Florida 33199, USA
}

\begin{abstract}
Both the incidence and prevalence of coral disease are rapidly increasing, and as a consequence, many studies involving coral microbial associates have been conducted. However, very few of these have considered microbial functional genes. This is an underutilized approach for studying coral disease etiology which is capable of revealing the molecular processes of the coral microbial community. This review presents a summary of the known microbial functional genes that have been linked to coral health and disease. Overall functional gene diversity tended to be lower in healthy corals than diseased or bleached corals, and respiration and photosynthesis functional genes appeared to be crucial to coral health. Genes associated with the nitrogen cycle were the most studied, were highly represented within the coral holobiont, and their expression often shifted in diseased or stressed individuals. Carbon metabolism, such as fatty acid and amino acid catabolism, also tended to shift in unhealthy corals. Genes associated with sulfite respiration as well as dimethylsulfoniopropionate degradation have been detected, although they have yet to be directly associated with coral disease. In addition, genes associated with xenobiotic degradation, antibiotic resistance, virulence, and oxidative stress may all be involved in maintaining coral health. However, the links between these functional genes and their roles in interacting with the coral host are not clear. Continuing identification of coral-associated microbial functional genes within the coral holobiont should facilitate advances in the field of coral health and disease.
\end{abstract}

KEY WORDS: Etiology $\cdot$ Biogeochemical cycling $\cdot$ Holobiont $\cdot$ Functional diversity $\cdot$ Antibiotic resistance Resale or republication not permitted without written consent of the publisher

\section{THE IMPORTANCE OF FUNCTIONAL GENES}

Despite the recent interest elicited by the observed and well-documented increase in coral disease incidence and prevalence (Weil et al. 2006, Harvell et al. 2007, Haapkylä et al. 2011, Weil et al. 2012), knowledge of many aspects of coral disease etiology is incomplete, including interactions among the environment, causative agents of disease, microbial associates, and coral hosts (Work et al. 2008, Aeby et al. 2011). In particular, a close examination of the intricate dynamics of the microbial community associated with corals would be beneficial to gain an under- standing of how corals may develop resistance and resilience to disease and bleaching (Rosenberg et al. 2007, Bourne et al. 2009, Garren \& Azam 2012). The coral holobiont is defined as the coral animal and its microbial (eukaryotic, bacterial, archaeal, and viral) associates (Rowan 1998, Rohwer et al. 2002). In recent years, it has become increasingly clear that the microbial component of the holobiont plays an essential part in maintaining the health of the coral. The majority of microbiology-based studies involving coral diseases have focused on identifying bacterial communities using the $16 \mathrm{~S}$ rRNA gene. However, there was no strong correlation between taxonomic 
diversity and the specific microbial habitat in which the bacteria were detected, as there was with functional gene diversity (Dinsdale et al. 2008). In most cases, the taxonomic identification of a microbe does not elucidate its functional role, giving little indication as to a microbe's importance. To complicate matters further, bacterial species with the same 16S rRNA gene sequence may play different roles in an ecosystem (Ainsworth et al. 2010). On the other hand, bacterial species with different 16S rRNA gene sequences may be functionally redundant, with more than one taxonomic group satisfying a single niche (Allison \& Martiny 2008). For these reasons, it is crucial that studies begin to examine the role that microbes play in coral health and disease, rather than focus on identification of the microbes present. As an example, 'Type A' Gammaproteobacteria have commonly been associated with healthy fragments of the coral Acropora, and it has been proposed that a disruption in this population may alter the entire microbial community (Kvennefors et al. 2010, 2012) and increase the coral's vulnerability to disease and bleaching. However, the role of Type A Gammaproteobacteria in the coral holobiont has not been established. Functional gene analysis is capable of revealing this role. Microbial associates also play crucial roles in the biogeochemical cycling of coral nutrients (Mouchka et al. 2010). Analyzing the changes in microbial functional genes provides a method for identifying an imbalance in these cycles. Characterization of the genes that are abundant within the microbial community would also be an effective way to investigate the dynamics and interactions between the members of the coral holobiont. For example, the presence of the functional gene coding for ribulose bisphosphate carboxylase (RuBisCo) would indicate that autotrophy is associated with that particular holobiont member (He et al. 2012).

The known microbial functional genes associated with corals can be considered within 7 functional groups: nitrogen-, sulfur-, carbon-, antibiotic resistance-, xenobiotic-, virulence-, and oxidative stressassociated genes. These functional genes have been targeted in several ways. Some studies probed microbial communities for specific genes (Barneah et al. 2007, Beman et al. 2007, Sussman et al. 2009, Bourne et al. 2011, 2013, Pollock et al. 2010, Glas et al. 2012, Lema et al. 2012), some analyzed genomes of entire microbial communities using next generation sequencing techniques (Wegley et al. 2007, Dinsdale et al. 2008, Vega Thurber et al. 2009, Littman et al. 2011, Kvennefors et al. 2012), and some used functional gene arrays such as the GeoChip 3.0 (Kimes et al. 2010). Aside from the few studies listed here, very little research has been conducted on functional genes of coral microbial associates. In an effort to facilitate further research in this field, the present review categorically examines the known functional genes that have been documented within the coral holobiont, and how their function may be related to coral disease and bleaching.

\section{FUNCTIONAL GENE DIVERSITY}

Functional gene diversity within the coral microbial community can provide an insight into the molecular processes available within the holobiont. This has been demonstrated for the microbial community associated with the coral Porites astreoides. The majority of functional genes were heterotrophic and involved with the uptake of carbon, sulfur, and nitrogen (Wegley et al. 2007). The high proportion of microbial heterotrophic and carbon-acquisition genes implies that the coral microbial community does not fix a significant amount of carbon, and may obtain its nutrients through byproducts of the coral or zooxanthellae. Many of the genes in the $P$. astreoides microbial community were from all 3 domains of life (Bacteria, Archaea, Eukarya), evidence that the biogeochemical cycling of nutrients depends on the diversity of the entire holobiont. Coral health may deteriorate if members of the holobiont are no longer present to perform their biogeochemical roles, which can be indicated by a shift in functional genes (Table 1). For instance, 20\% of coral-associated microbial functional genes are respirationrelated, compared to only $3 \%$ of terrestrial microbial habitats (Dinsdale et al. 2008). The high abundance of respiration genes, both aerobic and anaerobic, suggests that diverse respiration pathways are key processes in the microbial coral holobiont. The number of respiration genes was significantly reduced in bleached Acropora millepora, dropping from an initial 39 to $23 \%$. Photosynthesis genes (microbial) also decreased from 48 to $30 \%$ (Littman et al. 2011). In contrast, an analysis of microbial gene expression demonstrated that photosynthesis genes were significantly upregulated in the microbial mat of an active black band disease (BBD) infection, when compared to BBD microbial mats that were suspended in sea water (Frias-Lopez et al. 2004).

Several questions arise from the analysis of overall functional gene diversity in the coral holobiont. 
Table 1. Changes in the diversity of functional genes associated with microbial processes and various coral conditions

\begin{tabular}{|c|c|c|c|}
\hline Coral condition & $\begin{array}{l}\text { Microbial process associated } \\
\text { with functional genes }\end{array}$ & $\begin{array}{l}\text { Change in } \\
\text { diversity }\end{array}$ & Source \\
\hline Bleaching & $\begin{array}{l}\text { Photosynthesis, respiration } \\
\text { Metabolic pathways (membrane transport, } \\
\text { fatty acid, amino acid, sugar alcohol, di-, and } \\
\text { oligo- saccharide metabolism), virulence } \\
\text { pathways, oxidative stress, sulfur cycling }\end{array}$ & $\begin{array}{l}\text { Decrease } \\
\text { Increase }\end{array}$ & Littman et al. (2011) \\
\hline $\begin{array}{l}\text { Thermal and } \\
\text { pH stress }\end{array}$ & $\begin{array}{l}\text { Nitrogen cycling, sulfur cycling, virulence } \\
\text { pathways, oxidative stress }\end{array}$ & Increase & Vega Thurber et al. (2009) \\
\hline Yellow band disease & $\begin{array}{l}\text { Nitrification, cellulose degradation, } \\
\text { carbon fixation, lignin degradation }\end{array}$ & Increase & Kimes et al. (2010) \\
\hline \multirow[t]{2}{*}{ Black band disease } & $\begin{array}{l}\text { Amino acid ABC transporters, photosystem I, } \\
\text { AraC-type DNA binding domain proteins }\end{array}$ & Increase & Frias-Lopez et al. (2004) \\
\hline & Sulfate reduction, sulfur oxidation & Increase & $\begin{array}{l}\text { Barneah et al. (2007), } \\
\text { Bourne et al. (2011, 2013), } \\
\text { Glas et al. (2012) }\end{array}$ \\
\hline
\end{tabular}

When do these shifts in functional genes occur, and are they a consequence or cause of bleaching and disease? Can a change in abundance of microbial photosynthesis- and respiration-related functional genes predict coral bleaching or BBD? The answers to these questions have the potential to provide useful information for predicting and monitoring coral bleaching and disease.

It has been shown that the diversity and relative proportion of microbial functional genes are specific to individual environments, with distinct functional genomes dominant in each microbial habitat, and that the diversity of functional genes associated with coral microbial habitats is less than that of largerscale marine habitats such as the water column of a marine atoll (Dinsdale et al. 2008). Microbes that have formed a tight symbiosis with their host often demonstrate a loss in functional gene diversity, as the host provides a controlled environment, and an array of functional genes is no longer necessary for survival (Ochman \& Moran 2001, Rio et al. 2003, Toh et al. 2006). The reduction in microbial functional diversity associated with coral emphasizes the strength of the symbiotic relationships that have developed between the coral animal and its microbial associates. Specifically, functional gene diversity of secondary metabolic and virulence pathways, cell signaling pathways, and membrane transport pathways were all reduced (Dinsdale et al. 2008). Intriguingly, bleached Acropora millepora revealed an increase in each of these pathways (Littman et al. 2011), and it may be that an increase in the diversity of these pathways indicates the presence of nonintrinsic microbes that have not developed an evolutionary relationship with the coral host. Therefore, it can be hypothesized that an increase in the listed pathways indicates a shift in the coral microbial population toward an unhealthy state.

Certain microbial ribotypes are specific to environmental conditions (Littman et al. 2009), coral species or genera (Rohwer et al. 2002, Littman et al. 2009), and microhabitats within the individual coral (Sweet et al. 2011). Therefore, the diversity and relative proportion of functional genes may also be specific to these environments. Three microhabitats have been identified within coral, viz. the surface mucopolysaccharide layer (SML), the coral tissue, and the coral skeleton. The possibility that microbial functional genes may be coral species specific, as well as the partitioning of certain functional genes within the various compartments of the coral, is relatively unexplored. One study briefly mentioned differences in the functional gene diversity between the SML and tissue of coral (Kimes et al. 2010), although the concept of functional gene partitioning was not fully developed, as it was not the primary focus of the study. In that study, a significantly higher level of diversity and abundance of microbial functional genes was found in the tissue samples of Montastraea faveolata compared to the SML samples; the functional gene diversity associated with the coral skeleton was not investigated. Possible explanations for the reduced functional gene diversity in the SML could be that more symbiotic microbes were present in the SML compared to the coral tissues, or perhaps microbial diversity was restricted in the SML due to antimicrobial compounds (see 'Antibiotic resistanceassociated functional genes' below). Further work expanding upon the functional gene partitioning will tease out the answers to these questions, and the 
roles that microbes play in the various species and microhabitats of corals.

The functional genome of the microbial community is present in viruses, as they often pick up extra DNA during replication (Dinsdale et al. 2008). In the coral holobiont, functional genes associated with carbohydrate metabolism and virulence had a higher frequency in the viral community compared to the microbial community, while respiration and photosynthesis genes were lower (Dinsdale et al. 2008). The viral genome can encode essential processes such as nitrogen fixation and act as storage of functional genes for these essential processes (Dinsdale et al. 2008, Marhaver et al. 2008). The field of viral functional genomics in coral research is relatively untouched and deserves further attention. Questions such as the viral capacity to store and distribute functional genes among coral populations may be essential to understanding how the viral community contributes to the health of the holobiont.

The study by Kimes et al. (2010) also compared the overall functional gene diversity of healthy and yellow band disease (YBD)-infected coral. Numerous genes were common to both healthy and YBD colonies of Montastraea faveolata, with approximately half of all genes associated with carbon, nitrogen, and sulfur cycling. Differences between diseased and healthy individuals included an increase in nitrification and cellulose degradation genes in the diseased corals (Kimes et al. 2010), many originating from microbes commonly associated with coral diseases such as the family Vibrionaceae and the genus Aspergillus (Harvell et al. 2007). Healthy corals tended to have less microbial functional gene diversity than diseased corals, once again suggesting a tight microbial symbiosis with the healthy coral host (Kimes et al. 2010). This study provides an example of how microbial functional gene diversity may serve as an indicator in the context of monitoring coral health, with an increase in diversity indicating a decline in coral health.

\section{Nitrogen-associated functional genes}

The presence of nitrogen cycling within the coral holobiont is highly evident and mentioned in several microbial functional gene studies. Genes for nitrogen fixation, archaeal nitrification genes, fungal ammonification, and fungal ammonia assimilation genes have all been detected in the coral holobiont (summarized by Kimes et al. 2010). In a healthy Porites astreoides holobiont, genes were identified for every process of the nitrogen cycle, with the exception of denitrification (Wegley et al. 2007). The entire nitrogen cycle was detected in the Montastraea faveolata coral holobiont (Kimes et al. 2010). Specific nitrogen-cycling genes detected include nifH and nifD (nitrogenase for fixing nitrogen), amo (ammonia monooxygenase for nitrification), hao (hydroxylamine oxioreductase, which catalyzes the reduction of hydroxylamine to nitrite), nar, nir, nor, nos (all reductases for denitrification), ghd (glutamate dehydrogenase for ammonia assimilation), and ure (urease) genes (Fig. 1). Many of these genes were detected from all 3 domains of life.

The abundance and diversity of nitrogen-associated genes detected in multiple studies emphasize the importance of nitrogen biogeochemical cycling in the coral holobiont. Although no shift in nitrogen metabolism genes was detected when Acropora millepora fragments were bleached (Littman et al. 2011), both a decrease in $\mathrm{pH}$ and a rise in temperature caused an increase in nitrogen cycling and nitrogen metabolism genes associated with the Porites compressa holobiont (Vega Thurber et al. 2009). Similarly, tissue samples from YBD-infected and healthy Montastraea faveolata colonies revealed significant differences in nitrification genes (Kimes et al. 2010). There is evidence that an addition of nutrients such as ammonium inhibits coral growth (Ferrier-Pagès et al. 2000),

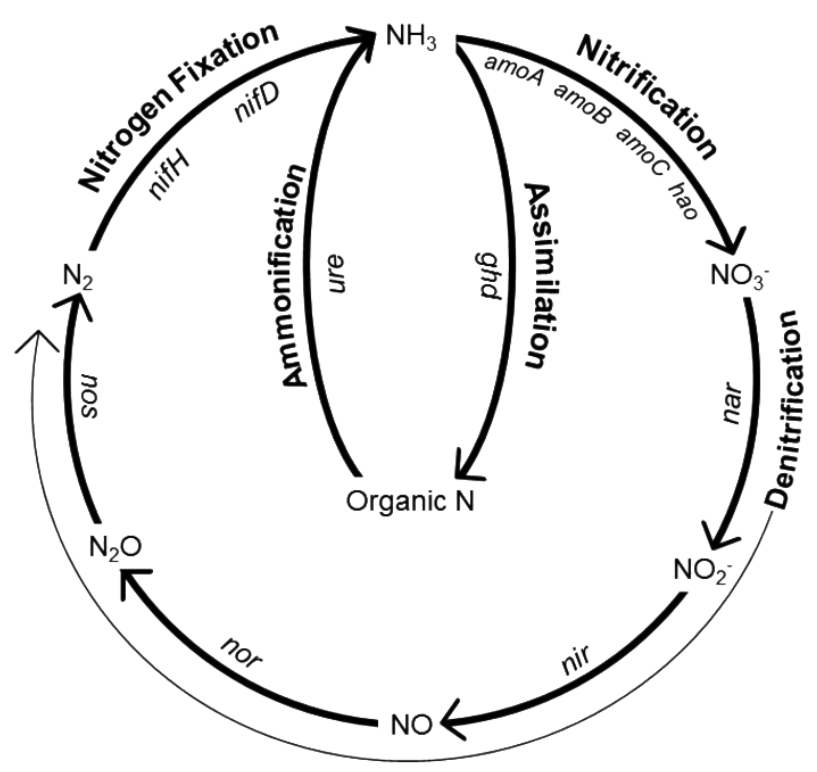

Fig. 1. Summary of nitrogen-associated functional genes detected in the coral holobiont. Genes are italicized, and biogeochemical processes are in bold. This figure represents known functional genes and is not exhaustive of the nitrogen-associated processes present in the coral holobiont 
which may be induced by a disturbance in the biogeochemical cycling of the holobiont. In studies such as this, specific nitrogen-associated functional genes, including nif, amo, hao, nar, nir, nor, nos, ghd, and ure, may be useful targets for monitoring the state of the nitrogen cycle. Additionally, shifts detected in these nitrogen cycle genes may serve as early warning signs for coral response to eutrophication and stressors such as acidification and temperature increase.

Nitrogen fixation may be a key process in the coral holobiont, as reefs are often oligotrophic and nitrogen is a limiting nutrient (Suzuki \& Casareto 2011). Diazotrophs (free-living, nitrogen-fixing prokaryotes) such as cyanobacteria may play an essential role in the holobiont by providing this limiting nutrient to the coral host (Lesser et al. 2004, 2007b). Other potentially important nitrogen fixers occur in the Alpha- and Gammaproteobacteria groups, as well as Spirochaetes, Firmicutes, and Archaea (Kimes et al. 2010, Kvennefors et al. 2012). One gene commonly used to identify the presence of diazotrophs is nifH, which encodes the dinitrogenase iron protein (Shashar et al. 1994, Lema et al. 2012). Inside the coral skeleton, several bacterial isolates were discovered containing the nifH gene, indicating the possibility of nitrogen fixation specifically within the calcareous skeleton (Shashar et al. 1994). Another study investigated nifH diversity of 3 different Great Barrier Reef coral species (Lema et al. 2012). Diversity was relatively low compared to the water column; a total of 1344 nifH sequences yielded only 26 distinct operational protein units (OPUs). A greater diversity of nifH genes was found in coral tissue samples compared to SML samples, again reflecting the limited functional gene diversity within the SML. Interestingly, $71 \%$ of Alphaproteobacteria OPUs were related to Rhizobiales, which are diazotrophs associated with the root nodules of legume plants (Lema et al. 2012). One of the nifH genes was also associated with a known methanotroph. As with overall functional gene diversity, the presence and frequencies of the nifH OPUs were specific to species of coral (Lema et al. 2012). While the relative abundance of genes must be examined with caution, as one organism may contain multiple copies of a gene, it appears that individual microbes and their functional nifH genes associate closely with specific coral species. Analysis of the nifH gene has provided useful insight into the function of diazotrophs in the coral holobiont. Specifically, this approach revealed that the coralassociated nifH gene is primarily of Alphaproteobacteria origin, is partitioned in the coral skeleton and/or tissue, is distinct from that found in the water column, and appears to be specific to individual species of coral, suggesting that it is an essential component to the health of the holobiont.

Ammonia oxidation, or the conversion of ammonia to nitrite and nitrate, is the rate-limiting step in nitrification. The genes typically associated with ammonia oxidation are $a m o B, a m o C$, and $a m o A$ which code for ammonia monooxygenase, and the hao gene which codes for hydroxylamine oxidoreductase. In a survey of 9 different coral species in 4 different locations, amo genes associated with corals did not overlap with amo genes from the water column, indicating that those nitrifying bacteria were coral specific (Beman et al. 2007). The amo genes did not appear to be specific to individual coral species, although a higher diversity in archaeal amo genes was found in Diploria strigosa than in Porites spp. (Beman et al. 2007). When the presence of these genes was studied in healthy and YBD-infected Montastraea faveolata, $a m o B$ and $a m o C$ were found only in the diseased individuals, while amo $A$ and hao were found in both (Kimes et al. 2010). The higher diversity of amo genes in diseased individuals may indicate that ammonia waste production is higher in infected corals than healthy corals. The presence of amo genes in both healthy and diseased corals also suggests that microbes capable of ammonia oxidation may be essential to the health of coral to detoxify the ammonia.

\section{Sulfur-associated functional genes}

The sulfur biogeochemical cycle has been linked to an important and global polymicrobial coral disease, $\mathrm{BBD}$, which involves sulfur-oxidizing and sulfatereducing bacteria (Richardson 2004). The dsr gene indicates the presence of sulfate-reducing bacteria, and has been the target of several BBD studies (Barneah et al. 2007, Bourne et al. 2011, Glas et al. 2012). The $d s r$ genes detected in the BBD microbial mat primarily belong to the genus Desulfovibrio (Barneah et al. 2007, Bourne et al. 2011) and were documented to increase in abundance during the development of BBD infection (Glas et al. 2012). The continued presence and increase of the $d s r$ gene in BBD infections indicate that sulfate reduction may be a key process in the disease etiology. The occurrence of sulfur oxidation has also been confirmed in BBD by detection of the $\operatorname{sox} B$ gene (Bourne et al. 2013). The majority of sulfur-oxidizing bacteria identified via the soxB gene were of Rhodobacteraceae origin, with 
low abundance and diversity. Combined, these studies confirm that sulfur oxidation and reduction are components crucial to BBD etiology, and require further investigation if their roles in the disease process are to be understood.

Barneah et al. (2007) did not detect the dsr gene in healthy portions of BBD-infected individual corals using quantitative PCR. However, Kimes et al. (2010) provided evidence that the sulfur cycle is active in the healthy coral holobiont. Using the GeoChip 3.0, over 500 discrete sequences corresponding to the $d s r$ gene were detected in both healthy and YBDinfected Montastraea faveolata (Kimes et al. 2010), indicating abundant sulfur respiration within the holobiont. Because the dsr gene was abundant in both healthy and diseased individuals, it can be concluded that sulfite respiration is not linked to YBD pathogenesis. On the other hand, when Porites compressa fragments were $\mathrm{pH}$ stressed, the abundance of sulfur metabolism genes increased (Vega Thurber et al. 2009). This result also occurred when Acropora millepora experienced a bleaching event (Littman et al. 2011). It is interesting to note that sulfur metabolisms did not increase during infection of coral by YBD, which lyses coral tissue at relatively low rates compared to other diseases (Santavy et al. 1999), whereas the relative abundance of sulfur metabolisms increased in response to $\mathrm{pH}$ stress and bleaching, both of which are not known to degrade tissue. However, in order to understand why sulfur metabolism functional genes increase in developments such as bleaching, stress, and presumably BBD, but not YBD, their role must first be understood in the healthy holobiont.

In healthy Porites astreoides, genes for assimilating the organic sulfur compound glutathione were 3 times more abundant than genes present for assimilating inorganic sulfur. This suggests a glutathione source in the holobiont, possibly from the host coral, that the microbes are able to utilize (Wegley et al. 2007). There is also evidence of dimethylsulfoniopropionate (DMSP) degradation to dimethyl sulfide (DMS) and acrylic acid within the coral holobiont (Raina et al. 2009). The genes $d d d D$, $d d d R$, and $d d d L$ are all associated with this degradation process, and were detected in bacteria from healthy coral, including Arhodomonas, Pseudomonas, and Roseobacter. The response of these genes has yet to be studied under stressed conditions. For example, does the proportion of organic to inorganic sulfur assimilation genes change during the process of bleaching or disease? How are DMSP degradation genes affected? A disruption in sulfur biogeochemical cycling has been linked to several human diseases such as inflammatory bowel disease and other intestinal diseases (Carbonero et al. 2012), yet BBD is currently the only coral disease to which the biogeochemical sulfur cycle has been linked. Analysis of sulfur cycle genes associated with coral diseases can help to bridge this gap in knowledge.

\section{Carbon-associated functional genes}

A metagenomic study of Porites astreoides found many bacterial genes for the uptake and processing of sugars and proteins, while genes for transport of amino acids and fatty acids were absent (Wegley et al. 2007). The genes present in this case reflect the composition of coral mucus, which is generally sugars and proteins, with few amino acids and fatty acids (Bythell \& Wild 2011). This correlation strengthens the concept that the functional genes present in a system can indicate available substrates and active microbial processes within that system. The direct correlation between coral mucus composition and genes which uptake the components of coral mucus is disrupted when the coral bleaches. Bacterial genes involving fatty acid and amino acid metabolisms, as well as sugar alcohol, di-, and oligosaccharide metabolisms all increased in bleached Acropora millepora holobiont (Littman et al. 2011). The upregulation of these carbon metabolism genes indicates that alternative carbon sources may be available in bleached corals compared to healthy corals.

A shift in carbon metabolism genes was also evident in YBD. While many bacterial and archaeal metabolisms such as the Calvin Cycle, reductive acetyl-CoA pathway, reverse Krebs cycle, and methanotrophy were present in both YBD and healthy tissue samples of Montastraea faveolata, significant changes were detected in the genes associated with carbon fixation, cellulose degradation, and lignin degradation (Kimes et al. 2010). The increase of these metabolic functional genes may be attributed to opportunistic microbes taking advantage of nutrients released by the lysing of the coral tissue. Intriguingly, it was shown that an increase of cellulose degradation genes in diseased samples was due to Vibrio vulnificus, a known marine pathogen (Strom \& Paranjpye 2000). This implies that $V$. vulnificus may target the symbiotic zooxanthellae associated with corals since it can be assumed that they are the source of cellulose. Further investigation will reveal whether $V$. vulnificus is indeed the causative agent of YBD or is a secondary pathogen, and whether cellulose 
degradation genes are key virulence factors for this pathogen.

\section{Antibiotic-resistance-associated functional genes}

Antibiotics are found naturally in many environments, including the SML of coral. In the coral holobiont, 25 to $75 \%$ of bacteria display antimicrobial activity (Ritchie 2006, Shnit-Orland \& Kushmaro 2009), and it has been proposed that this activity may inhibit the growth of potentially pathogenic bacteria in order to protect the coral animal (Rosenberg et al. 2007). This microbial protection mechanism is known as the coral probiotic hypothesis (Reshef et al. 2006). The resulting competition between beneficial and harmful microbes within the coral holobiont has been viewed as an arms race of antimicrobial compound production versus expression of resistance mechanisms (Kvennefors et al. 2012). Bacteria resistant to multiple antibiotics have already been detected in the marine environment, particularly in sediments (Mudryk 2005, Vignaroli et al. 2012). Many marine fish farms are heavily dosed with antibiotics, facilitating the selection for antibiotic-resistant marine microbes (Nogales et al. 2011). The immediate concern here may not be apparent since coral are not typically treated by antibiotics. However, antibioticresistance genes can be transferred through horizontal gene transfer, potentially affecting the antimicrobial arms race of the coral holobiont. It has also been found that metal resistance is commonly associated with, and may increase, antibiotic resistance (BakerAustin et al. 2006). This is troublesome, as an increase in anthropogenic metals in the marine environment may further facilitate antibiotic-resistant microbes. The acquisition of antibiotic-resistance genes by a potential coral pathogen may give it a significant advantage to resist antimicrobial compounds produced by beneficial microbial associates of the coral holobiont (Nogales et al. 2011). Antibiotic and toxic compound-resistance genes have already been identified in the Porites astreoides holobiont (Wegley et al. 2007), although they do not necessarily belong to a pathogen. The known coral pathogen Vibrio coralliilyticus already demonstrates resistance to antimicrobial activity (Kimes et al. 2012, Kvennefors et al. 2012). Despite the distinct possibility of potential coral pathogens becoming antibiotic resistant, the acquisition and distribution of antibiotic-resistance genes within the coral holobiont is largely unknown. With the continuing selection for antibiotic resistance in marine microbes, in-depth analysis will be required in order to determine the level of threat to the health of the coral holobiont.

\section{Xenobiotic-associated functional genes}

The effects of xenobiotics on the coral animal have been studied in detail, revealing specific genes that respond to heavy metal stress (Morgan et al. 2005), oil dispersants, vinblastine (Venn et al. 2009), pesticides, and antifouling paints (Downs et al. 2012). However, very little is known regarding the influence of xenobiotics on the microbial component of the coral holobiont. The deficiency of knowledge in this area is in part due to the lack of study, and in part to the vast range of xenobiotics that may be associated with marine environments. Only 1 coral study has analyzed the microbial functional genes associated with xenobiotics, comparing YBD tissues to healthy tissues of Montastraea faveolata (Kimes et al. 2010). A total of 2100 xenobiotic degradation genes were identified, with significant differences between healthy and diseased individuals in genes associated with copper resistance/reduction, benzene by-product degradation, benzene, toluene, ethylbenzene, and xylene degradation, nitroaromatics degradation, and pesticide/fungicide/herbicide degradation. The underlying reason for shifts in xenobiotic-degradation genes and how they are associated with the disease is not clearly understood. Metal homeostasis and resistance genes, including iron-, arsenic-, tellurium-, mercury, and copper-associated genes, were detected in both healthy and diseased corals (Kimes et al. 2010). The presence of these genes in healthy and diseased individuals implies that microbial xenobiotic maintenance and degradation may be an essential component to the health of the coral holobiont as a whole. As mentioned previously, Reshef et al. (2006) introduced the coral probiotic hypothesis, outlining a scenario in which the coral animal is dependent upon its rapidly evolving microbial associates to develop defense mechanisms against pathogens. By the same logic, coral may also be dependent upon microbial associates to evolve xenobiotic degradation and maintenance mechanisms, such as those listed above. In a future ocean that may be heavily dosed with xenobiotics, this is an important issue that deserves consideration. The role of microbial xenobiotic degradation and maintenance in the coral holobiont is a distinct gap in our understanding of corals and should be the subject of further investigation in order to understand how the coral holobiont as a whole may develop resistance against these compounds. 


\section{Virulence-associated functional genes}

Iraola et al. (2012, p. 1) defined virulence as 'the relative capacity of a microbe to cause damage in a host.' Accordingly, any functional gene that assists a potential pathogen in this capacity is considered a virulence gene. Microbial virulence genes have been detected in both healthy and stressed coral holobionts. Many virulence genes were present within the healthy Porites astreoides holobiont (Wegley et al. 2007), suggesting that microbes with pathogenic capacities may reside in a healthy holobiont, waiting for the opportunity to proliferate. An increase in microbial virulence genes for adhesion, resistance to antibiotics and toxins, and pathogenicity islands was observed in thermally and $\mathrm{pH}$-stressed $P$. compressa (Vega Thurber et al. 2009), and an increase in virulence genes, specifically proteolysis, was revealed in bleached Acropora millepora (Littman et al. 2011). Although these studies do not give the specific genes associated with virulence, it is clear that an increase in virulence genes is indicative of a stressed holobiont, and may represent an increase in potential pathogens (primary or secondary). Further in-depth analysis of these virulence genes may prove beneficial in identifying potential pathogens.

One study was successful in modeling and predicting the pathogenicity of fully sequenced humanassociated bacteria based on key virulence genes (Iraola et al. 2012). Using a set of 120 genes as a proxy for microbial pathogenicity, the authors were able to accurately distinguish known pathogens from bacteria that were not pathogenic. Using this study as an example, ascertaining key virulence genes in the coral microbial metagenome may assist in identifying the causative agent(s) of coral diseases.

To date, several virulence genes have been identified in coral pathogens belonging to the genus Vibrio (Table 2). Toxin P is a proline-rich peptide encoded by a vgr-like gene that has been identified in $V$. shiloi (Banin et al. 2001) and V. coralliilyticus (de O Santos et al. 2011). A gene coding for a zinc metalloprotease, $v c p A$, has also been identified in $V$. coralliilyticus
(Sussman et al. 2008, 2009, Pollock et al. 2010). Upon sequencing the entire genome of $V$. coralliilyticus, a suite of virulence genes was uncovered (de O Santos et al. 2011, Kimes et al. 2012). Using this genetic information, de O Santos et al. (2011) were able to directly study the effects of the vcpA gene on the virulence capacity of $V$. coralliilyticus. $\triangle V c p A$ mutants still demonstrated a high virulence capability by compensating with increased hemolytic activity, identifying another crucial virulence factor in the coral pathogen. Kimes et al. (2012) identified 136 key virulence genes in $V$. coralliilyticus, including those associated with motility, host degradation, quorum sensing, antimicrobial resistance, secretion, and transcriptional regulation. These studies demonstrate the potential power of using functional genes to identify and assess molecular targets, which can then be a focus of future studies in the ongoing effort to mitigate coral diseases.

\section{Oxidative stress-associated functional genes}

Very few studies have concentrated on coralassociated bacterial oxidative stress, instead focusing on the coral and zooxanthellae members of the holobiont (DeSalvo et al. 2008, Császár et al. 2009, Voolstra et al. 2009). Several studies have demonstrated that bacterial associates of corals experience oxidative stress, as do their eukaryotic cohorts. In the healthy Porites astreoides holobiont, microbial oxidative-stress genes and DNA repair genes were present (Wegley et al. 2007). When bleached, an increase in each of these genes was detected in the coral Acropora millepora (Littman et al. 2009). When $P$. compressa coral fragments were stressed with excess nutrients, microbial genes for catalase, peroxidase, and superoxide dismutase all increased (Vega Thurber et al. 2009). It is evident through these studies that stressors such as excess nutrients and bleaching induce the upregulation of microbial oxidative stress genes. However, it is unclear whether the increase in these genes is beneficial to the holobiont.

Table 2. Specific virulence genes directly associated with known Vibrio pathogens of corals

\begin{tabular}{|lllc|}
\hline Virulence gene & Pathogen & Function & Source \\
\hline $\begin{array}{l}\text { vcpA (zinc- } \\
\text { metalloprotease) }\end{array}$ & V. coralliilyticus & $\begin{array}{c}\text { Causes zooxanthellae photoinhibition and } \\
\text { causes coral tissue lesions }\end{array}$ & $\begin{array}{c}\text { Sussman et al. (2008, 2009), } \\
\text { Pollock et al. (2010), } \\
\text { de O Santos et al. (2011) } \\
\text { vgr-like (Toxin P) }\end{array}$ \\
$\begin{array}{l}\text { V. shiloi } \\
\text { V. coralliilyticus }\end{array}$ & $\begin{array}{c}\text { Proline-rich peptide, inhibits photosynthesis } \\
\text { of zooxanthellae }\end{array}$ & $\begin{array}{c}\text { Banin et al. (2001) } \\
\text { de O Santos et al. (2011) }\end{array}$ \\
\hline
\end{tabular}


For instance, superoxide dismutase is considered an important virulence factor in the coral pathogen Vibrio shiloi (Rosenberg \& Falkovitz 2004). The detected increase in microbial oxidative-stress functional genes may be attributed to the invasion of nonintrinsic microbes such as $V$. shiloi, or to the beneficial microbes striving to protect the holobiont. Identification of the specific source of oxidative stress functional genes from coral-associated microbes may be important in understanding whether upregulation of these genes is serving to protect the coral holobiont from reactive oxygen species, or rather indicating increased presence of a virulence factor by a potential pathogen.

\section{MOLECULAR TECHNIQUES AND CAVEATS}

Although many genes have been associated with the coral holobiont, this does not mean they are all actively transcribed and translated. The presence of a gene simply represents the potential to carry out the function associated with the gene. Once potential coral-associated microbial genes are identified, they must be further investigated. This is proving to be challenging. Analysis of the transcriptome of prokaryote communities can be difficult because prokaryotic mRNA does not contain a poly-A tail for primers to bind to, as eukaryotes do. To circumvent this problem, 1 study used RNA arbitrarily primed PCR (RAP$\mathrm{PCR}$ ) to determine the differential gene expression between the microbial mat of an active BBD infection and a BBD mat suspended in sea water (Frias-Lopez et al. 2004). Several gene transcripts were upregulated in the active BBD infection, including photosystem I, $\mathrm{ABC}$ transporters of amino acids, and AraC-type DNA-binding domain proteins. RAP-PCR is advantageous because it allows the identification of genes that change transcription levels in prokaryotes. However, the method relies upon random primers and may miss transcripts that do not bind the random primers. Another study looked beyond the genome using nuclear magnetic resonance to analyze the proteome of the coral pathogen Vibrio coralliilyticus. Significant changes were detected in metabolites such as betaine, glutamine, and succinate when $V$. coralliilyticus was subject to increased temperature (Boroujerdi et al. 2009). Although the technique was not particularly sensitive and showed high variability between replicates, studying the proteome reflected which genes were actively being transcribed and translated. A more sensitive, albeit more expensive, method for analyzing the proteome is the use of liq- uid chromatography and tandem mass spectrophotometry in conjunction with genome sequencing. Kimes et al. (2012) used this method to positively identify 126 key virulence genes that are upregulated in $V$. coralliilyticus cultured at warmer temperatures. As these studies demonstrate, understanding the vast complexity of coral health and disease will take a combination of emerging '-omic' techniques. When genomics, transcriptomics, and proteomics are combined, they provide powerful analysis tools that uncover the mechanisms and drivers of disease, and guide the search for coral disease resolutions.

\section{CONCLUSIONS}

Just as the presence of a microbe in diseased individuals does not prove that the microbe is the cause of disease (Lesser et al. 2007a, Pollock et al. 2011), it should not be assumed that the presence or activity of a functional gene is associated with the etiology of a disease. In each of the cases discussed above, it is not yet known whether the changes in microbial functional genes were tied to disease etiology, either in association with primary or secondary pathogens, or whether the observed shifts were an indirect consequence of the disease. However, it is clear that microbial functional genes are a dynamic component of the coral holobiont and that there are differences in gene expression between healthy, diseased, and physiologically stressed corals. Based on these pioneering studies, it is apparent that analysis of microbial functional genes has the potential to indicate coral stress, provide an early warning sign of disease and bleaching, identify disease mechanisms, and ascertain microbial associates essential to the health of the coral. Identifying the roles of microbial functional genes in the coral holobiont is a crucial step to understanding coral health and disease, and it is a step we have just begun to take.

Acknowledgements. I thank L. Richardson for thoughtful comments on the manuscript. I was supported by the FIU MBRS RISE Program. This is contribution number 266 from the Tropical Biology Program at Florida International University.

\section{LITERATURE CITED}

Aeby GS, Williams GJ, Franklin EC, Kenyon J, Cox EF, Coles S, Work TM (2011) Patterns of coral disease across the Hawaiian archipelago: relating disease to environment. PLoS ONE 6:e20370 
Ainsworth TD, Thurber RV, Gates RD (2010) The future of coral reefs: a microbial perspective. Trends Ecol Evol 25: 233-240

Allison SD, Martiny JBH (2008) Resistance, resilience, and redundancy in microbial communities. Proc Natl Acad Sci USA 105:11512-11519

Baker-Austin C, Wright M, Stepanauskas R, McArthur J (2006) Co-selection of antibiotic and metal resistance. Trends Microbiol 14:176-182

Banin E, Khare S, Naider F, Rosenberg E (2001) Proline-rich peptide from the coral pathogen Vibrio shiloi that inhibits photosynthesis of zooxanthellae. Appl Environ Microbiol 67:1536-1541

> Barneah O, Ben-Dov E, Kramarsky-Winter E, Kushmaro A (2007) Characterization of black band disease in Red Sea stony corals. Environ Microbiol 9:1995-2006

> Beman JM, Roberts KJ, Wegley L, Rohwer F, Francis CA (2007) Distribution and diversity of archaeal ammonia monooxygenase genes associated with corals. Appl Environ Microbiol 73:5642-5647

> Boroujerdi AFB, Vizcaino MI, Meyers A, Pollock EC and others (2009) NMR-based microbial metabolomics and the temperature-dependent coral pathogen Vibrio coralliilyticus. Environ Sci Technol 43:7658-7664

> Bourne DG, Garren M, Work TM, Rosenberg E, Smith GW, Harvell CD (2009) Microbial disease and the coral holobiont. Trends Microbiol 17:554-562

> Bourne DG, Muirhead A, Sato Y (2011) Changes in sulfatereducing bacterial populations during the onset of black band disease. ISME J 5:559-564

> Bourne DG, van der Zee MJJ, Botté ES, Sato Y (2013) Sulfuroxidizing bacterial populations within cyanobacterial dominated coral disease lesions. Environ Microbiol Rep 5:518-524

Bythell JC, Wild C (2011) Biology and ecology of coral mucus release. J Exp Mar Biol Ecol 408:88-93

Carbonero F, Benefiel AC, Alizadeh-Ghamsari AH, Gaskins HR (2012) Microbial pathways in colonic sulfur metabolism and links with health and disease. Front Physiol 3: 448

> Császár NBM, Seneca FO, van Oppen MJH (2009) Variation in antioxidant gene expression in the scleractinian coral Acropora millepora under laboratory thermal stress. Mar Ecol Prog Ser 392:93-102

de O Santos E, Alves N Jr, Dias GM, Mazotto AM and others (2011) Genomic and proteomic analyses of the coral pathogen Vibrio coralliilyticus reveal a diverse virulence repertoire. ISME J 5:1471-1483

> DeSalvo MK, Voolstra CR, Sunagawa S, Schwarz JA and others (2008) Differential gene expression during thermal stress and bleaching in the Caribbean coral Montastraea faveolata. Mol Ecol 17:3952-3971

> Dinsdale EA, Edwards RA, Hall D, Angly F and others (2008) Functional metagenomic profiling of nine biomes. Nature 452:629-632

> Downs CA, Ostrander GK, Rougee L, Rongo T and others (2012) The use of cellular diagnostics for identifying sublethal stress in reef corals. Ecotoxicology 21:768-782

Ferrier-Pagès C, Gattuso J, Dallot S, Jaubert J (2000) Effect of nutrient enrichment on growth and photosynthesis of the zooxanthellate coral Stylophora pistillata. Coral Reefs 19:103-113

Frias-Lopez J, Klaus J, Bonheyo G, Fouke B (2004) Bacterial community associated with black band disease in corals. Appl Environ Microbiol 70:5955-5962
Garren M, Azam F (2012) New directions in coral reef microbial ecology. Environ Microbiol 14:833-844

Glas MS, Sato Y, Ulstrup KE, Bourne DG (2012) Biogeochemical conditions determine virulence of black band disease in corals. ISME J 6:1526-1534

Haapkylä J, Unsworth RKF, Flavell M, Bourne DG, Schaffelke B, Willis BL (2011) Seasonal rainfall and runoff promote coral disease on an inshore reef. PLoS ONE 6: e16893

> Harvell D, Jordan-Dahlgren E, Merkel S, Rosenberg E and others (2007) Coral disease, environmental drivers, and the balance between coral and microbial associates. Oceanography 20:172-195

He Z, Deng Y, Zhou JZ (2012) Development of functional gene microarrays for microbial community analysis. Curr Opin Biotechnol 23:49-55

Iraola G, Vazquez G, Spangenberg L, Naya H (2012) Reduced set of virulence genes allows high accuracy prediction of bacterial pathogenicity in humans. PLoS ONE 7:e42144

Kimes NE, Van Nostrand JD, Weil E, Zhou J, Morris PJ (2010) Microbial functional structure of Montastraea faveolata, an important Caribbean reef-building coral, differs between healthy and yellow-band diseased colonies. Environ Microbiol 12:541-556

Kimes NE, Grim CJ, Johnson WR, Hasan NA and others (2012) Temperature regulation of virulence factors in the pathogen Vibrio coralliilyticus. ISME J 6:835-846

Kvennefors ECE, Leggat W, Kerr CC, Ainsworth TD, Hoegh-Guldberg O, Barnes AC (2010) Analysis of evolutionarily conserved innate immune components in coral links immunity and symbiosis. Dev Comp Immunol 34: 1219-1229

Kvennefors ECE, Sampayo E, Kerr C, Vieira G, Roff G, Barnes AC (2012) Regulation of bacterial communities through antimicrobial activity by the coral holobiont. Microb Ecol 63:605-618

> Lema KA, Willis BL, Bourne DG (2012) Corals form characteristic associations with symbiotic nitrogen-fixing bacteria. Appl Environ Microbiol 78:3136-3144

Lesser MP, Mazel CH, Gorbunov MY, Falkowski PG (2004) Discovery of symbiotic nitrogen-fixing cyanobacteria in corals. Science 305:997-1000

Lesser MP, Bythell JC, Gates RD, Johnstone RW, HoeghGuldberg O (2007a) Are infectious diseases really killing corals? Alternative interpretations of the experimental and ecological data. J Exp Mar Biol Ecol 346:36-44

> Lesser MP, Falcón LI, Rodríguez-Román A, Enríquez S, Hoegh-Guldberg O, Iglesias-Prieto R (2007b) Nitrogen fixation by symbiotic cyanobacteria provides a source of nitrogen for the scleractinian coral Montastraea cavernosa. Mar Ecol Prog Ser 346:143-152

Littman RA, Willis BL, Pfeffer C, Bourne DG (2009) Diversities of coral-associated bacteria differ with location, but not species, for three acroporid corals on the Great Barrier Reef. FEMS Microbiol Ecol 68:152-163

Littman R, Willis BL, Bourne DG (2011) Metagenomic analysis of the coral holobiont during a natural bleaching event on the Great Barrier Reef. Environ Microbiol Rep 3:651-660

> Marhaver KL, Edwards RA, Rohwer F (2008) Viral communities associated with healthy and bleaching corals. Environ Microbiol 10:2277-2286

Morgan MB, Edge SE, Snell TW (2005) Profiling differential gene expression of corals along a transect of waters adja- 
cent to the Bermuda municipal dump. Mar Pollut Bull 51: 524-533

Mouchka ME, Hewson I, Harvell CD (2010) Coral-associated bacterial assemblages: current knowledge and the potential for climate-driven impacts. Integr Comp Biol 50:662-674

Mudryk Z (2005) Occurrence and distribution antibiotic resistance of heterotrophic bacteria isolated from a marine beach. Mar Pollut Bull 50:80-86

Nogales B, Lanfranconi MP, Pina-Villalonga JM, Bosch R (2011) Anthropogenic perturbations in marine microbial communities. FEMS Microbiol Rev 35:275-298

> Ochman H, Moran N (2001) Genes lost and genes found: evolution of bacterial pathogenesis and symbiosis. Science 292:1096-1099

Pollock FJ, Wilson B, Johnson WR, Morris PJ, Willis BL, Bourne DG (2010) Phylogeny of the coral pathogen Vibrio coralliilyticus. Environ Microbiol Rep 2:172-178

Pollock FJ, Morris PJ, Willis BL, Bourne DG (2011) The urgent need for robust coral disease diagnostics. PLoS Pathog 7:e1002183

Raina JB, Tapiolas D, Willis BL, Bourne DG (2009) Coralassociated bacteria and their role in the biogeochemical cycling of sulfur. Appl Environ Microbiol 75:3492-3501

Reshef L, Koren O, Loya Y, Zilber-Rosenberg I, Rosenberg E (2006) The coral probiotic hypothesis. Environ Microbiol 8:2068-2073

Richardson LL (2004) Black band disease. In: Rosenberg E, Loya Y (eds) Coral reef health and disease. Springer, New York, NY, p 325-336

Rio RV, Lefevre C, Heddi A, Aksoy S (2003) Comparative genomics of insect-symbiotic bacteria: influence of host environment on microbial genome composition. Appl Environ Microbiol 69:6825-6832

Ritchie KB (2006) Regulation of microbial populations by coral surface mucus and mucus-associated bacteria. Mar Ecol Prog Ser 322:1-14

Rohwer F, Seguritan V, Azam F, Knowlton N (2002) Diversity and distribution of coral-associated bacteria. Mar Ecol Prog Ser 243:1-10

Rosenberg E, Falkovitz L (2004) The Vibrio shiloi/Oculina patagonica model system of coral bleaching. Annu Rev Microbiol 58:143-159

Rosenberg E, Koren O, Reshef L, Efrony R, ZilberRosenberg I (2007) The role of microorganisms in coral health, disease and evolution. Nat Rev Microbiol 5: 355-362

Rowan R (1998) Diversity and ecology of zooxanthellae on coral reefs. J Phycol 34:407-417

Santavy DL, Peters EC, Quirolo C, Porter JW, Bianchi CN (1999) Yellow-blotch disease outbreak on reefs of San Blas Islands, Panama. Coral Reefs 18:97

Shashar N, Cohen Y, Loya Y, Sar N (1994) Nitrogen fixation (acetylene reduction) in stony corals: evidence for coralbacteria interactions. Mar Ecol Prog Ser 111:259-264

Editorial responsibility: Garriet Smith, Aiken, South Carolina, USA
Shnit-Orland M, Kushmaro A (2009) Coral mucusassociated bacteria: a possible first line of defense. FEMS Microbiol Ecol 67:371-380

> Strom MS, Paranjpye RM (2000) Epidemiology and pathogenesis of Vibrio vulnificus. Microbes Infect 2:177-188

Sussman M, Willis BL, Victor S, Bourne DG (2008) Coral pathogens identified for white syndrome (WS) epizootics in the Indo-Pacific. PLoS ONE 3:e2393

> Sussman M, Mieog JC, Doyle J, Victor S, Willis BL, Bourne DG (2009) Vibrio zinc-metalloprotease causes photoinactivation of coral endosymbionts and coral tissue lesions. PLoS ONE 4:e4511

Suzuki Y, Casareto BE (2011) The role of dissolved organic nitrogen (DON) in coral biology and reef ecology. In: Dubinsky Z, Stambler N (eds) Coral reefs: an ecosystem in transition. Springer, New York, NY, p 207-214

Sweet MJ, Croquer A, Bythell JC (2011) Bacterial assemblages differ between compartments within the coral holobiont. Coral Reefs 30:39-52

Toh H, Weiss B, Perkin S, Yamashita A, Oshima K, Hattori M, Askov S (2006) Massive genome erosion and functional adaptations provide insights into the symbiotic lifestyle of Sodalis glossinidius in the tsetse host. Genome Res 16:149-156

> Vega Thurber R, Willner-Hall D, Rodriguez-Mueller B, Desnues C and others (2009) Metagenomic analysis of stressed coral holobionts. Environ Microbiol 11: 2148-2163

Venn AA, Quinn J, Jones R, Bodnar A (2009) P-glycoprotein (multi-xenobiotic resistance) and heat shock protein gene expression in the reef coral Montastraea franksi in response to environmental toxicants. Aquat Toxicol 93: 188-195

Vignaroli C, Luna GM, Rinaldi C, Di Cesare A, Danovaro R, Biavasco F (2012) New sequence types and multidrug resistance among pathogenic Escherichia coli isolates from coastal marine sediments. Appl Environ Microbiol 78:3916-3922

Voolstra CR, Schnetzer J, Peshkin L, Randall CJ, Szmant AM, Medina M (2009) Effects of temperature on gene expression in embryos of the coral Montastraea faveolata. BMC Genomics 10:627

> Wegley L, Edwards R, Rodriguez-Brito B, Liu H, Rohwer F (2007) Metagenomic analysis of the microbial community associated with the coral Porites astreoides. Environ Microbiol 9:2707-2719

- Weil E, Smith G, Gil-Agudelo DL (2006) Status and progress in coral reef disease research. Dis Aquat Org 69:1-7

Weil E, Irikawa A, Casareto B, Suzuki Y (2012) Extended geographic distribution of several Indo-Pacific coral reef diseases. Dis Aquat Org 98:163-170

- Work TM, Richardson LL, Reynolds TL, Willis BL (2008) Biomedical and veterinary science can increase our understanding of coral disease. J Exp Mar Biol Ecol 362: $63-70$

Submitted: January 15, 2013; Accepted: August 26, 2013 Proofs received from author(s): November 18, 2013 